\title{
La evolución del ciclo ganadero argentino en la segunda fase del modelo sustitutivo de importaciones
}

\section{The Evolution of the Argentine Livestock Cycle in the Second Phase of the Import Substitution Mode}

\author{
Nicolás Arceo* \\ Facultad Latinoamericana de Ciencias Sociales, Buenos Aires, Argentina, \\ nicolasarceo@gmail.com
}

Resumen. El abandono del modelo agroexportador en la década de 1930 es frecuentemente asociado con el inicio de un supuesto proceso de estancamiento de la producción agropecuaria pampeana y, en particular, de la producción ganadera, proceso que se habría intensificado desde mediados de la década de 1940. A lo largo de este trabajo se intentará demostrar que la ganadería pampeana, lejos de ingresar en un periodo de franca decadencia, accedió a una fase de crecimiento como consecuencia de la expansión del mercado local.

Palabras clave: modelo agroexportador; producción agropecuaria; producción ganadera.

Abstract. The crisis of the agro-export model in the 1930s is often associated with the beginning of stagnation in farming production, especially in livestock production, process that would have been stronger since mid-1940s. Throughout this paper, we aim to demonstrate that the livestock, far from entering a period of frank decline, began a phase of growth because of the expansion of local market.

Key words: Agroexport model; farming production; livestock production.

JEL: N8; O13; Q1.

Fecha de recepción: 14 de septiembre de 2016. Fecha de aceptación 5 de enero de 2017.

* Investigador del Consejo Nacional de Investigaciones Científicas y Técnicas (CONICET) y del Área de Economía y Tecnología de la Flacso.

Am. Lat. Hist. Econ., sep.-dic., 2017, pp. 161-192 | DOI: 10.18232/alhe.v24i3.813 


\section{INTRODUCCIÓN}

$\mathrm{E}$ abandono del modelo agroexportador en la década de 1930 es frecuentemente asociado con el inicio de un supuesto proceso de estancamiento de la producción agropecuaria pampeana y, en particular, de la producción ganadera, proceso que se habría intensificado desde mediados de la década de $1940 .{ }^{1}$ A lo largo de este trabajo se intentará demostrar que la ganadería pampeana, lejos de ingresar en un periodo de franca decadencia, accedió a una fase de crecimiento como consecuencia de la expansión del mercado local.

Dicho proceso de estancamiento sin embargo, no evitó que Argentina perdiera el liderazgo que exhibía en el mercado mundial cárnico en las primeras décadas del siglo Xx. De todas formas, dicha declinación no estuvo determinada por el sesgo antiexportador que según diversos autores (Díaz-Alejandro, 1975; Mallon y Sourrouille, 1973; Martínez de Hoz, 1967) se fue consolidando desde comienzos de la década de 1930, sino por modificaciones sustantivas que acontecieron en el mercado internacional de la carne vacuna tras la finalización de la segunda guerra mundial.

En efecto, el papel protagónico que tuvo Argentina en el comercio mundial de este bien salario estuvo estrechamente vinculado a la evolución de la demanda británica, ya que el grueso de sus exportaciones -al menos hasta mediados del siglo XX- estuvo dirigido a dicho mercado. ${ }^{2}$ Así, el comercio entre estos dos países daba cuenta hasta finales de la década de 1930 de una porción sustantiva del comercio internacional. Por lo tanto, la declinación de la demanda británica, a la cual se le sumó la falta de dinamismo de los mercados que aceptaban la importación de carne vacuna desde países con presencia de aftosa -como Argentina-, fueron la causa determinante de la pérdida de relevancia de la ganadería pampeana ${ }^{3}$ en el mercado internacional. Sin embargo, esto no implicó que la producción

\footnotetext{
${ }^{1}$ Esta caracterización se constata en diversas escuelas del pensamiento económico. Así, por ejemplo, Bisang (2008) sostiene que: "A lo largo del periodo sustitutivo, las producciones agropecuarias entraron -por diversas razones- en un cono de sombra; mientras que la industria sustitutiva se convertía en el motor de la economía, el agro (más que la ganadería y la lechería) permanecía ajeno tanto al dinamismo productivo interno, como a los cambios operados internacionalmente en el marco de la denominada revolución verde." (p. 188). A su vez, desde otras vertientes, Alfredo Martínez de Hoz (1967) sostuvo que: "La disminución y el estancamiento de la producción agropecuaria incidió a su vez en las posibilidades de crecimiento de nuestra economía en general, provocando estrangulamiento externo causante de nuestras crisis periódicas de balance de pagos" (p. 114).

${ }^{2}$ Es decir, esta estrecha relación con Gran Bretaña estuvo vigente hasta el agotamiento del modelo agroexportador en Argentina, que tuvo lugar como consecuencia de la crisis mundial de la década de 1930.

${ }^{3}$ En 1960, 71\% del stock de ganado vacuno se localizaba en la región pampeana (Peretti y Gómez, 1991).
} 
ganadera haya permanecido estancada durante el proceso sustitutivo de importaciones que se inició a partir de la crisis mundial de la década de 1930, tal como se analizará en este trabajo.

En términos del estado del arte, cabe mencionar que la inmensa mayoría de la bibliografía se concentra en el análisis de la retracción verificada en la agricultura pampeana a lo largo de la primera fase del modelo sustitutivo de importaciones, de 1930 a 1958. A partir de dicho análisis se extrapolan, en muchos casos, conclusiones a la totalidad del periodo sustitutivo, así como de las distintas producciones que lo componen. En este sentido podemos encontrar autores como Martínez de Hoz (1967), Mallon y Sourrouille (1973), Díaz-Alejandro (1975) y Bisang (2008), entre otros, que caracterizan al conjunto del periodo como, al menos, de estancamiento de la producción agropecuaria. Tal como se analizará en este trabajo la producción ganadera lejos estuvo de ingresar en una etapa de estancamiento y retracción, en particular durante la vigencia de la segunda fase del modelo sustitutivo de importaciones.

Por otro lado, independientemente de la corriente historiográfica de la que se trate o de la escuela económica en que se inscriben los distintos autores, la tradicional competencia por el uso del suelo entre la agricultura y la ganadería en la región pampeana ha sido explicada, casi sin excepciones, a través de la teoría del ciclo ganadero. En este sentido, podemos encontrar autores estructuralistas de la Comisión Económica para América Latina (CEPAL) como Cuccia (1983 y 1988), autores con un enfoque más tradicional de la teoría económica como Gluck (1977), Parellada (1987), Peretti y Gómez (1991), Fernández (2011), González Fraga (2005) y Brusca y Bisang (2016), entre otros, y visiones asociadas a autores que propugnan una mayor intervención del Estado en la economía que utilizaron a lo largo de sus investigaciones este marco teórico, como Giberti (1974), Azcuy Ameghino (2007) y Basualdo (2006).

En esta perspectiva, las diversas investigaciones realizadas sobre la evolución de la producción ganadera bajo el periodo en consideración se focalizaron por lo general en el análisis de su competencia con la agricultura, en las transformaciones tecnológicas que impactaron en el sector y en la relación entre el ciclo ganadero, el precio de la carne vacuna, el consumo interno de este producto y la evolución de los salarios reales. En este sentido, se enmarcan los trabajos de Guadagni (1964), Guadagni y Petrecolla (1965), Reca (1972), Reca y Gaba (1973), Parellada (1987 y 1988), entre otros $y$, aunque diversos autores ponen de manifiesto la relevancia de las exportaciones cárnicas en la evolución del ciclo ganadero local, en particular Cuccia (1988), no se evalúa la evolución del ciclo ganadero local en relación con el experimentado en los principales países importadores. 
El análisis de esta relación junto con la reevaluación de la evolución de la ganadería durante la segunda fase del modelo sustitutivo de importaciones, son el objetivo central del presente trabajo, el cual se divide en tres secciones. La primera está destinada a realizar una breve caracterización del mercado internacional de carne vacuna tras la finalización del segundo conflicto bélico mundial. En la segunda sección, se analizarán las características que la expansión de la ganadería y el ciclo ganadero presentaron en Argentina durante la segunda fase del modelo sustitutivo de importaciones (1958-1977). ${ }^{4}$ Por último, se evaluará la relación existente entre la evolución del ciclo ganadero local y el imperante en los principales países importadores de carne vacuna argentina.

\section{CONTEXTO INTERNACIONAL}

La estabilización de la demanda británica a partir de la década de 1930 condujo a un relativo estancamiento del mercado internacional de carne vacuna. Esta situación perduró hasta mediados de la década de 1950 cuando, como consecuencia del incremento del consumo a nivel internacional, se registró una significativa expansión del comercio internacional. Sin embargo, en esta nueva etapa, tanto Argentina como Gran Bretaña perdieron importancia relativa ante el surgimiento de nuevos países importadores y exportadores. ${ }^{5}$

La relevancia de Gran Bretaña como principal importador de carne vacuna había comenzado a decaer desde mediados de los años treinta, tendencia que se intensificó desde la finalización de la segunda guerra mundial. Mientras que en el segundo quinquenio de la década del treinta el mercado británico reportaba $80 \%$ de las importaciones mundiales de carne vacuna, dicha participación se había reducido a 55\% en el primer quinquenio de los años cincuenta y a $44.5 \%$ en el segundo quinquenio de dicha década. Este proceso se produjo centralmente por el creciente abastecimiento interno, por la modificación de los hábitos alimentarios de la población y por el aumento en el consumo de sustitutos, como la carne de cerdo (Azcuy Ameghino, 2007).

La reducción de las compras británicas repercutió directamente en la participación de las exportaciones argentinas en el mercado mundial, ya

${ }^{4}$ Respecto a la periodicidad adoptada véase, entre otros, Basualdo (2006).

${ }^{5}$ Azcuy Ameghino (2007) señala que, dada la naturaleza del complejo cárnico local, "la decadencia de la demanda inglesa se proyectó inmediatamente sobre él, ratificando que la razón central de su existencia había sido abastecer desde las pampas al Reino Unido, mediante una red de negocios cuyo núcleo estaba constituido por el pool anglo-yanqui y las empresas navieras y de seguros inglesas" (p. 13). 
que registraron una tendencia descendente desde mediados de los años treinta: mientras que en el periodo 1934-1938 Argentina daba cuenta de $54.5 \%$ de las exportaciones mundiales de carne vacuna, en el segundo quinquenio de la década del cincuenta había caído a 35.9\%. De todas formas, se debe remarcar que la reducción de las exportaciones argentinas al mercado británico no sólo estuvo determinada por la contracción de las compras externas de dicho país, sino también por la creciente competencia con terceros países (Azcuy Ameghino, 2007).

La pérdida del liderazgo de Argentina en el mercado internacional cárnico fue un proceso que caracterizó toda la etapa, determinando que a comienzos de los años setenta el país fuera un actor secundario en el comercio mundial de este producto. Se debe señalar que este proceso no sólo estuvo relacionado con la contracción de las compras británicas como se señala, sino también con la incapacidad del país de diversificar sus exportaciones hacia terceros mercados.

Para Martínez de Hoz (1967) y Díaz-Alejandro (1975), la pérdida de importancia en el mercado internacional de carne vacuna fue una consecuencia directa de la inexistencia de saldos exportables que permitieran abastecer la demanda externa, lo que determinó que Argentina fuera desplazada por otros competidores a nivel internacional. Si bien efectivamente las ventas externas quedaron atadas a la disponibilidad de excedentes en el mercado doméstico, este proceso fue acompañado también por crecientes dificultades para colocar exportaciones de carne vacuna en el mercado internacional.

Las dificultades afrontadas por Argentina para acceder al mercado internacional cárnico fueron compartidas por diversos países del cono sur del continente. Asimismo, durante esta etapa se verificó una elevada intervención de los distintos gobiernos tanto en Argentina como en Brasil, Paraguay y Uruguay tendente a garantizar una oferta local elevada que posibilitara la existencia de precios accesibles de la carne vacuna para el conjunto de la población.

La presencia de fiebre aftosa en estos países fue un elemento decisivo en los obstáculos que se presentaron para la exportación a terceros países. ${ }^{6}$ Desde finales de la segunda guerra mundial, el mercado internacional de carne vacuna se conformó con base en dos circuitos. Por un lado, el libre

\footnotetext{
${ }^{6}$ La existencia de fiebre aftosa fue detectada en la década de 1870 en Argentina, Chile, Uruguay y Brasil. A lo largo de las primeras décadas del siglo XX dicha enfermedad se expandió a Perú, Bolivia, Paraguay, Venezuela, Colombia y finalmente Ecuador, entre otros países. A su vez, en 1947 afectó severamente a México que, ante un brote de fiebre aftosa por la importación de animales enfermos desde Brasil, tuvo restringidas las exportaciones hacia Estados Unidos por casi una década (véase Melo y López, 2002). Sobre el impacto de la fiebre aftosa en la producción cárnica de Argentina véase O’Connell (1986).
} 
de aftosa, compuesto fundamentalmente por las exportaciones de Oceanía hacia Estados Unidos, ${ }^{7}$ Canadá y Japón, y por otro, el circuito donde se detecta la presencia de la enfermedad y que agrupa las exportaciones desde América Latina hacia Europa, África y el Medio Oriente.

La existencia de fiebre aftosa en los rodeos argentinos es de larga data -se registraron fehacientemente los primeros focos en la década de 1970 (Azcuy Ameghino, 2007, p. 116), pero fue con posterioridad a la segunda guerra mundial cuando su presencia se constituyó en una barrera sanitaria para la diversificación de los destinos de las exportaciones cárnicas. ${ }^{8}$

Los orígenes del circuito no aftósico se remontan a finales de los años veinte, cuando Estados Unidos decretó la prohibición del ingreso de carne vacuna desde países donde se constataba la presencia de la enfermedad. Si bien el mercado estadunidense no revestía importancia para las exportaciones cárnicas argentinas en los años treinta, el incremento de las compras externas por parte de este país en la posguerra implicó la imposibilidad de acceder a uno de los mercados más dinámicos. Es más, las políticas llevadas adelante por Estados Unidos en materia sanitaria fueron replicadas por otros países como Canadá y Japón, contribuyendo a consolidar el circuito no aftósico. ${ }^{9}$

La consolidación de un circuito comercial con carne libre de aftosa en la posguerra les permitió a los países de Oceanía acceder a este mercado sin competidores y a precios notoriamente más elevados que los registrados en el circuito aftósico. De todas formas, el destino de las exportaciones cárnicas de los países de Oceanía hacia el circuito no aftósico posibilitó una leve recuperación de los precios en el otro circuito debido a la menor competencia. Este proceso significó un beneficio -aunque marginal- para Argentina (Azcuy Ameghino, 2007).

La conformación de dos circuitos diferenciados -uno con precios y cantidades crecientes y el otro con reducción de los volúmenes y de los

\footnotetext{
${ }^{7} \mathrm{Al}$ respecto Perren (2006) sostiene: "The split between the United States and Argentina over foot-and-mouth disease was partly a function on the way their livestock industries were managed. The extensive nature of the pampas meant that Argentina has always remained a range producer, whereas the United States had largely abandoned this method by the end of the nineteenth century. Thereafter the United States beef industry relied increasingly on feedlots with cattle concentrated in small areas, and its dairy industry was also managed in a similar way. In these circumstances, the disease spreads rapidly, and is regarded as a serious matter... They argued that for their intensively managed livestock industries the cost of the disease would be high if it ever became endemic, putting estimates of the overall loss of productivity for the industry, from infected, recovering and recovered animals at around 25 per cent" (p. 225).

${ }^{8}$ Las restricciones a las exportaciones cárnicas como consecuencia de la aftosa comenzaron a principios del siglo XX, cuando Gran Bretaña prohibió la exportación de ganado en pie.

${ }^{9}$ A lo largo del siglo XX se realizaron diversos intentos tendentes a erradicar la fiebre aftosa de los rodeos argentinos, aunque recién durante la década de 1990 se implementó un plan estricto de erradicación de la enfermedad.
} 


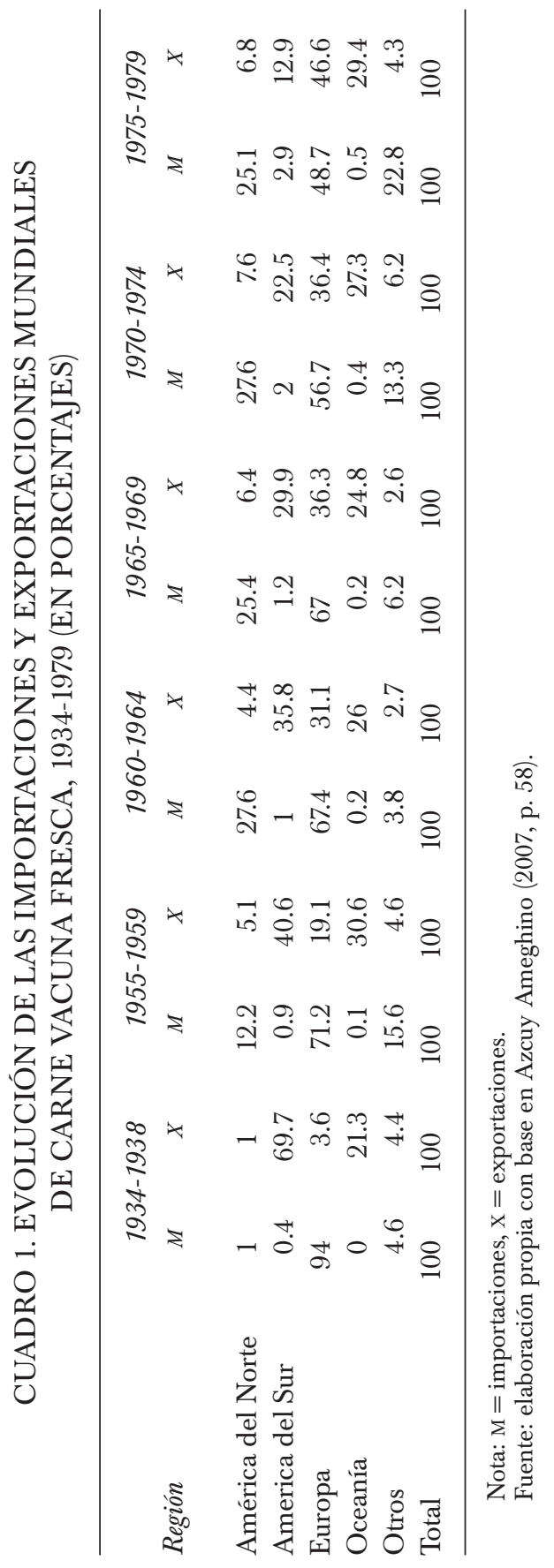


precios (como consecuencia de la caída de las compras británicas)- limitó significativamente las posibilidades argentinas de colocar mayores volúmenes de carne vacuna en el mercado internacional. El dinamismo del mercado estadunidense condujo a un notable incremento de su participación en las importaciones totales de carne vacuna, pasando de $1 \%$ en el periodo 1934-1938 a 27.6\% en el primer quinquenio de los años setenta (véase cuadro 1). Mientras tanto, la participación europea se reducía desde $94 \%$ a $56.7 \%$ en idéntico periodo. Por su parte, las exportaciones de América Latina circunscritas al circuito aftósico pasaron de representar 69.7\% de las exportaciones totales en el periodo 1934-1938 a sólo $22.5 \%$ en la primera mitad de la década de los setenta.

A su vez, el incremento de la demanda mundial de carne vacuna en la posguerra, fenómeno impulsado por la mejora de las condiciones de vida de la población, fue acompañado por un sensible aumento de la oferta propia en el continente europeo como consecuencia de las políticas de autosuficiencia alimentaria llevadas adelante por diversos países. En este sentido, el Reino Unido desarrolló políticas de autoabastecimiento desde los años sesenta, las cuales le permitieron aumentar el abastecimiento de su demanda interna con producción local desde 67\% en 1958 a 75\% de 1968 a 1969. Por otro lado, en 1967 se produjo un brote de fiebre aftosa en este país, lo que llevó a la suspensión de las importaciones de carne con hueso y menudencias provenientes de América del Sur, primero en forma provisional y, desde fines de 1969, en forma definitiva. ${ }^{10}$

Las políticas de autoabastecimiento establecidas en los países de la Comunidad Económica Europea (en adelante CEE) permitieron una expansión en la producción de carne vacuna a una tasa anual acumulativa de $3.6 \%$ en el periodo comprendido entre 1964 y 1974 . Sin embargo, este incremento no fue suficiente para reducir la dependencia de los mercados externos, en virtud de un crecimiento aún más significativo del consumo. ${ }^{11}$ Así, durante los años sesenta y comienzos de los setenta, parte del excedente generado por la reducción de las importaciones del Reino Unido (que en 1967 explicaba 25.3\% del total de las exportaciones argentinas de carne refrigerada) fue colocada en los países de la CEE (República Federal

${ }^{10}$ Desde ese momento, Gran Bretaña adoptó el criterio de riesgo mínimo, lo cual impidió el ingreso de la mayor parte de las exportaciones argentinas. Al respecto, Azcuy Ameghino (2007) sostiene: "La segunda línea de política sanitaria (y comercial) frente a la aftosa es la inaugurada por el Reino Unido en 1968 -adoptada en 1977 por la CEE-, denominada de riesgo mínimo, que se basa en autorizar el ingreso de carnes provenientes de zonas infectadas sólo bajo la forma de cortes deshuesados y madurados a temperaturas sobre cero a efectos de la destrucción del virus" (p. 109).

${ }^{11}$ Sobre el incremento de la producción de carne vacuna véase FAO (2016). 
Alemana, Italia, Holanda, Bélgica, España y Grecia) y en otros destinos considerados como no tradicionales.

Sin embargo, este panorama se modificó a lo largo de los años setenta, cuando las políticas introducidas en la CEE en la década previa permitieron una paulatina reducción de las importaciones de carne vacuna. Este fenómeno se produjo en el marco del estancamiento del consumo interno, producto de la desaceleración del crecimiento en las principales economías centrales. El mayor autoabastecimiento de carne vacuna y la simultánea reducción de la demanda condujeron al cierre progresivo de las importaciones por parte de la CEE a partir de $1974 .{ }^{12}$ Estos países lograrían finalmente el autoabastecimiento en 1978, para convertirse a mediados de los años ochenta en los principales exportadores mundiales. Cabe advertir que esta política de subsidios a la producción por parte de la CEE fue impugnada reiteradamente por Argentina en diversos foros internacionales y lo sigue siendo en la actualidad.

En definitiva, la debacle de las exportaciones argentinas de carne vacuna fue un proceso que abarcó la totalidad del periodo acompañando el ocaso de Gran Bretaña como el principal país importador de este producto. En efecto, mientras que en el primer quinquenio de la década de 1960 Argentina alcanzaba $26.8 \%$ del valor de las exportaciones mundiales, a comienzo de los años setenta su peso relativo había caído a 11.6\%, para posteriormente representar sólo 1.3\% del comercio mundial en 1975. En términos de las cantidades comerciadas, la participación de Argentina fue mayor dados los menores precios que percibía por no poder acceder a los mercados más dinámicos, aunque no se modificó la tendencia: a comienzos de los años sesenta el volumen físico de sus ventas externas reportaba $32.6 \%$ de las exportaciones mundiales y a mediados de los años setenta sólo explicaba $2.4 \%$ del total. ${ }^{13}$

Si bien desde la finalización de la segunda guerra mundial se asistió a una progresiva contracción de las exportaciones argentinas de carne vacuna, la ganadería pampeana lejos de verificar una etapa de contracción se expandió a tasas significativas, destinando los excedentes al abastecimiento del creciente mercado local.

${ }^{12} \mathrm{Al}$ respecto, Perren (2006) afirma: "Probably the largest disturbance to Argentine meat exports came after the extension for EC membership in 1973, bringing the United Kingdom, Irish Republic and Denmark into the Community. The entry of Britain meant that the world's greatest open market for food exports would in time be largely closed to outsiders. But even by 1974 the combined effect of EC tariff, etc. and its increased domestic production was having a serious effect on Europe's imports." (p. 178).

${ }^{13}$ La participación argentina en el mercado internacional de carne vacuna se estimó con base en FAO (2016). 
LA EXPANSIÓN DE LA PRODUCCIÓN GANADERA

\section{La expansión en el largo plazo}

El stock de ganado vacuno en Argentina evidenció una tendencia expansiva desde comienzos de la década de 1940 hasta el abandono del modelo sustitutivo de importaciones en $1977 .{ }^{14}$ Sin embargo, fue recién con la consolidación del modelo sustitutivo de importaciones a finales de los años cincuenta cuando se asistió a una recuperación significativa en el stock de ganado vacuno. En efecto, entre 1958 y 1977 el stock se expandió a una tasa anual acumulativa de $2.08 \%$, superando las tasas de crecimiento alcanzadas durante el modelo agroexportador en donde el stock creció a 1.61\% anual (1875-1930).

El dinamismo de la producción ganadera durante esta etapa se basó en la expansión del consumo local, que pasó desde los $73.6 \mathrm{~kg}$ por habitante por año en el periodo comprendido entre 1930 y 1945 a $84.2 \mathrm{~kg}$ entre 1945 y 1977, en un contexto de franca declinación de los mercados de exportación y de incremento en la participación de los asalariados en el ingreso. ${ }^{15}$

De todas formas, se debe señalar que el crecimiento del stock de ganado vacuno no fue un proceso lineal, por el contrario, se caracterizó por la presencia de numerosos periodos de expansión y contracción de stocks. El crecimiento del stock desde comienzos de la década del cuarenta y con intensidad a partir de 1945 perduró hasta 1952, cuando se inició una fase de liquidación como consecuencia de la caída en la rentabilidad relativa de esa actividad respecto a la agricultura. Se debe recordar que desde comienzos de los años cincuenta se instrumentaron diversas políticas tendentes a revertir el estancamiento que exhibía la producción agrícola a través del incremento de su rentabilidad tanto relativa como absoluta. El proceso de liquidación ganadero llevado adelante desde 1952 condujo a una reducción del precio de la carne vacuna en el mercado local -disminuyendo en términos reales $22.4 \%$ entre 1953 y 1957 -, permitiendo una significativa expansión del consumo interno, que promedió $94 \mathrm{~kg}$ por habitante en dicho periodo.

El estancamiento relativo de la producción ganadera en los años cincuenta se revirtió en la década siguiente. La consolidación del modelo sustitutivo de importaciones, lejos de frenar el desarrollo de la produc-

\footnotetext{
${ }^{14}$ Específicamente la expansión del stock de ganado vacuno se inició en 1942.

${ }^{15}$ Se debe señalar que ambos niveles de consumo fueron sensiblemente más elevados que los alcanzados entre 1914 y 1930, cuando el consumo de carne por habitante promedió $69.9 \mathrm{~kg}$ anuales.
} 
ción ganadera, posibilitó su expansión a tasas aún más elevadas que las registradas en los periodos previos, pasando el stock de ganado vacuno desde 41300000 cabezas en 1958 a 61100000 en 1977, momento en que se alcanzó el mayor stock de ganado vacuno de la historia de Argentina. Dicho crecimiento se sustentó en la mejora en los precios relativos como consecuencia de las diversas políticas orientadas a revertir el estancamiento del conjunto del sector agropecuario. A la vez, se asistió a un persistente incremento en la demanda como consecuencia del aumento en los ingresos de la población, ante una oferta que si bien también se expandió, lo hizo a menores tasas. La mayor demanda obedeció fundamentalmente al crecimiento del consumo doméstico, que absorbió $75.2 \%$ de la oferta de ganado vacuno en el periodo comprendido entre 1960 y 1977. Si bien las ventas externas continuaron desempeñando un papel relevante en la evolución del ciclo ganadero local, quedaron atadas a la disponibilidad de excedentes. Así, el aumento de los volúmenes exportados se producía esencialmente en las fases de liquidación de ganado, cuando la expansión de la oferta permitía abastecer al mercado local y simultáneamente ampliar los niveles de exportación.

Del lado de la oferta, se registró una sensible elevación de la productividad ganadera que se reflejó en un aumento en la carga animal por hectárea. Peretti y Gómez (1991, p. 274) estimaron un incremento en la receptividad ganadera de $31.1 \%$ en el periodo comprendido entre 1960 y 1977 debido a la mayor utilización de pasturas cultivadas -permanentes-, el uso de fertilizantes y las mejoras producidas sobre la infraestructura ganadera (véase cuadro 2).

Por otro lado, durante la segunda fase del modelo sustitutivo de importaciones se asistió a un acelerado proceso de remecanización del sector agropecuario pampeano, tras la contracción que habían experimentado las importaciones de maquinaria agrícola desde comienzos de la década de 1930 como consecuencia de la crónica escasez de divisas que enfrentó la economía argentina. ${ }^{16}$ Se debe señalar que durante la primera fase del modelo sustitutivo de importaciones no existieron políticas activas desde la esfera estatal tendentes al desarrollo de esta industria, proceso que estuvo asociado a las limitaciones propias que presentaba la incipiente indus-

${ }^{16} \mathrm{Al}$ respecto, Barsky y Gelman (2001) sostienen que si bien desde el siglo XIX se había desarrollado en Argentina una industria proveedora de implementos agrícolas y maquinaria, "el país dependía en gran medida del aprovisionamiento externo de estos elementos, y en los rubros más complejos, como es el caso de los tractores, la dependencia era total. También tenían fuerte peso las importaciones de segadoras, cosechadoras y sembradoras" (p. 314). A su vez, Bearzotti de Noceti (1983) afirma: "La industria argentina de la maquinaria agrícola había tenido un lento crecimiento inicial; los equipos se importaban libres de impuestos hasta 1930, año en que más por necesidades fiscales que por motivos proteccionistas su introducción fue gravada en un 10\% ad-valorem" (p. 45). 
CUADRO 2. CARGA ANIMAL DE GANADO VACUNO

EN LA REGIÓN PAMPEANA POR ZONA, 1960-1977

(EN CABEZAS VACUNAS POR HECTÁREA GANADERA ÚTIL)

\begin{tabular}{lcccc}
\hline & & & \multicolumn{2}{c}{$\begin{array}{c}\text { Diferencia } \\
\text { en porcentaje } \\
\text { Zona, año }\end{array}$} \\
Predominantemente agrícola & 1960 & 1974 & 1977 & \\
Predominantemente ganadera & 0.88 & 1.32 & 1.35 & 12.5 \\
Predominantemente mixta & 0.87 & 1.06 & 1.19 & 18.2 \\
Total región pampeana & 0.90 & 1.07 & 1.18 & 31.1 \\
\hline
\end{tabular}

a La delimitación de las zonas consideradas se basó en Gómez, Peretti, Pizarro y Cascardo (1991). La zona predominantemente agrícola abarca el norte de la provincia de Buenos Aires, sur de Santa Fe y el sudeste de la provincia de Córdoba. La zona predominantemente ganadera o de cría, incluye zonas no aptas para la agricultura, y se localiza en el centro-sur de la provincia de Buenos Aires. La zona mixta, apta para las dos producciones, incluye el oeste y el sur de la provincia de Buenos Aires, el sur de Entre Ríos, norte de Santa Fe y norte y oeste de la provincia de Córdoba.

Fuentes: elaboración propia con base en Gómez y Peretti (1991) y Gómez, Peretti, Pizarro y Cascardo (1991).

trialización. En efecto, Argentina no disponía aún de los insumos básicos requeridos para el desarrollo de esta producción, así como tampoco de la red de proveedores necesaria para la expansión de las tramas más complejas de la industria. Recién en los años cincuenta, con el desarrollo de la industria metalmecánica, siderúrgica y automotriz, existieron las condiciones objetivas para el desarrollo de la fabricación de maquinaria agrícola en el país. Es decir, el desarrollo de este tipo de industria requirió de la consolidación y profundización del modelo sustitutivo de importaciones.

No se puede dejar de resaltar que en los años cincuenta el desarrollo de este sector resultaba estratégico, ya que cumplía dos objetivos centrales. Por un lado, reducir la dependencia externa con el consiguiente ahorro de divisas; por el otro, impulsar la recuperación de la producción agrícola pampeana. En este sentido, las primeras políticas estatales orientadas a dinamizar la producción local de maquinaria y equipos agrícolas se remontan a fines de la década de 1940, cuando se declaró a dicha industria de interés nacional.

La remecanización del sector agrario pampeano impactó sensiblemente en la producción ganadera a través de la liberación de significativas porciones de superficie previamente destinadas a la cría de animales equinos. El stock de estos animales se redujo a la mitad en el periodo compren- 
dido entre 1955 y 1977, cayendo de 6000000 a 3000000 de cabezas. Por su parte, la menor rentabilidad relativa de la producción ovina respecto a la bovina observada desde mediados de los años sesenta condujo a una reducción del stock de este tipo de ganado de 46900000 a 34800000 cabezas en idéntico periodo. Se debe resaltar que ambos procesos facilitaron la liberación de cerca de 3000000 de hectáreas, que se destinaron -en mayor medida- a la producción ganadera, dada su elevada rentabilidad relativa respecto de la agricultura.

En definitiva, la consolidación del modelo sustitutivo de importaciones permitió, por un lado, expandir la demanda doméstica -producto de la elevación de los salarios reales- y, por otro, hizo posible un significativo crecimiento de la oferta, como consecuencia del proceso de remecanización y el desplazamiento del equino de la región pampeana. ${ }^{17} \mathrm{De}$ todas formas, se debe enfatizar que si bien la mayor parte de la superficie liberada por el proceso de remecanización se destinó a la ganadería, simultáneamente se produjo una expansión de la superficie agrícola, que pasó de 16100000 hectáreas en la campaña 1955-1956 a 21400000 en la campaña 1976-1977. ${ }^{18}$

Por lo tanto, el aumento en la receptividad ganadera y el desplazamiento del ovino y el equino permitieron que el crecimiento de la ganadería vacuna fuera acompañado por una expansión del área cultivada. A su vez, la expansión de esta última en detrimento de la ganadería vacuna estaba limitada por la necesidad de rotación en el uso de la tierra entre agricultura y ganadería con el fin de evitar la degradación de los suelos ante el bajo grado de difusión de los fertilizantes (Cuccia, 1988). ${ }^{19}$

\section{El comportamiento específico del ciclo ganadero durante la segunda fase del modelo sustitutivo de importaciones.}

La competencia por el uso del suelo entre la ganadería y la agricultura durante este periodo fue frecuentemente descrita en términos de la teoría del ciclo ganadero. En esta etapa, si bien se incrementó sensiblemente el stock de ganado vacuno, el mismo no siguió una tendencia constante, por

\footnotetext{
${ }^{17}$ Para un análisis detallado de las características que asumió el proceso de remecanización agrícola se puede consultar Bearzotti de Noceti (1983).

${ }^{18}$ Se considera la superficie sembrada con cereales y oleaginosas informada por la Bolsa de Cereales de Buenos Aires.

${ }^{19}$ Como sostiene Cuccia (1988): "el proceso de expansión del área cultivada en detrimento de la ganadería vacuna, al margen de los efectos cíclicos, se ve limitado por la necesidad de la rotación del uso de la tierra entre cultivos de granos y ganadería, dado el sistema de producción imperante en el área, donde se utilizan muy pocos fertilizantes” (p. 121).
} 
el contrario, atravesó periódicamente fases de liquidación o de retención de stocks, para luego expandirse nuevamente.

Se debe señalar que la importancia de las fluctuaciones en la evolución del stock de ganado vacuno radica en que no sólo influyen sobre el sector agropecuario, sino que afectan significativamente al conjunto de la economía. Por ejemplo, el incremento de la oferta en la fase de liquidación de stocks reduce el precio de la carne en el mercado local, permitiendo así una recomposición de los salarios reales, la disminución de la inflación y la expansión de las exportaciones cárnicas que facilitan el equilibrio del balance de pagos. Por el contrario, las fases de retención conducen por lo general a un aumento de su precio en el mercado local, con su consiguiente efecto sobre el nivel general de precios, los salarios reales y sobre los márgenes de la industria frigorífica de exportación (Cuccia, 1988).

Las distintas fases por las que atraviesa la producción ganadera están determinadas esencialmente por la evolución del precio de la carne vacuna y por su relación con los precios agrícolas. Es decir, ante un incremento en la rentabilidad relativa de la producción ganadera se inicia una fase de retención de ganado vacuno, con la consiguiente disminución de la superficie destinada a fines agrícolas. ${ }^{20}$ Por lo tanto, el aumento en la rentabilidad de la producción ganadera origina una contracción de la oferta, ya que a diferencia de otras actividades no posee la típica curva de oferta con pendiente positiva. Por el contrario, ante una elevación en el precio, en el corto plazo la cantidad ofrecida no sólo no se incrementa, sino que se reduce. Este comportamiento atípico se debe al doble carácter del ganado vacuno, que es simultáneamente un bien de consumo y un bien de capital. Esta característica conduce a que en la fase ascendente de los precios, los productores retengan ganado (en particular los vientres, que por ser bienes de capital, les permitirán expandir su producción futura). Contrariamente, la reducción del precio determina la conformación de una fase de liquidación, donde se observa una contracción del stock de ganado, ya que los productores liquidan la mayor cantidad de cabezas posible ante la perspectiva de una reducción del precio.

En el periodo comprendido entre 1960 y 1977 se registraron cinco fases de retención o liquidación de ganado vacuno, aunque mostraron distintas duraciones, ya que se observaron catorce años de retención de stocks y cuatro años de liquidación. A su vez, la intensidad de la variación del

\footnotetext{
${ }^{20}$ Esta competencia por el uso del suelo entre la producción ganadera y agrícola se producía durante esta etapa principalmente en la región pampeana. Según Cuccia (1988), la información existente indica que "las reducciones en las existencias de ganado vacuno se producen en la región pampeana, área en la que la ganadería vacuna compite con la agricultura, mientras que en el resto del país las existencias muestran una tendencia creciente y habrían registrado, en todo caso, fluctuaciones en su crecimiento pero no caídas absolutas" (p. 120).
} 
stock fue mucho más importante en las fases de retención, lo que determinó un incremento significativo en el stock de ganado vacuno (véase cuadro 3).

Tal como sostiene Cuccia (1988), es importante resaltar que siempre que no medien alteraciones en los factores naturales, los periodos de retención y liquidación definidos a partir de la evolución del stock de ganado bovino presentan determinadas regularidades con el comportamiento de otras variables que terminan de caracterizar el comportamiento sectorial. Este es el caso del nivel de faena, del peso de los animales faenados, de la tipificación de los mismos, de la superficie destinada a la agricultura y de la carga animal por hectárea.

Las variables identificadas están asociadas entre sí por razones biológicas, técnicas y económicas, aunque no necesariamente mantienen una relación estable, ya que se pueden producir modificaciones como consecuencia de fenómenos climáticos, de la aplicación de determinadas políticas económicas o de variaciones en las condiciones imperantes en el mercado internacional de carne vacuna, entre otras causas, lo cual determina que el ciclo ganadero sea una realidad esquiva. De todas formas, por lo general, las variables consideradas mostraron un comportamiento estable durante el periodo analizado, por ejemplo, la interrelación existente entre los distintos determinantes del ciclo ganadero y su comportamiento en el periodo comprendido entre 1960 y 1977 (véase cuadro 4).

Partiremos de la relación entre los precios relativos de la producción ganadera y la agrícola para evaluar el comportamiento de las restantes variables que explican la evolución del ciclo ganadero. Como se mencionó, ante una mejora en los precios relativos de la producción ganadera sobre la agrícola se inicia una fase de retención de ganado vacuno. En otras palabras, los ganaderos intentan expandir su producción y para ello retienen vientres para obtener más terneros, a la vez que retienen a los animales jóvenes para engordarlos lo máximo posible antes de su envío al mercado.

En consecuencia, el aumento en la rentabilidad relativa de la producción ganadera conducía a la contracción de la faena y a la reducción de la participación de los vientres en el total faenado, comportamiento que se debe a que las hembras son un bien de capital que permite acrecentar la producción futura. Este proceso ocurre incluso con anterioridad al inicio de una fase de retención. Es decir, la reducción de la participación de los vientres en la faena precede a la evolución de las existencias, aunque este fenómeno no es fácilmente observable al trabajar con datos anuales.

La participación de los vientres alcanza $36.1 \%$ de la faena en los ciclos de retención, en tanto que se eleva hasta $36.7 \%$ en las fases de liquidación. Esta reducida variabilidad se debe a que, como se mencionó, la participación de los vientres precede en al menos un año a la evolución del stock. En efecto, si se analiza la participación promedio de los vientres en la faena 


\section{CUADRO 3. CICLOS DE RETENCIÓN Y LIQUIDACIÓN DE GANADO BOVINO, DURACIÓN DEL CICLO Y TASA DE CRECIMIENTO DEL STOCK, 1960-1977}

$\begin{array}{llcc}\text { Periodo } & \text { Etapa } & \text { Duración en años } & \text { Tasa de crecimiento del stock }^{\mathrm{a}} \\ 1960-1962 & \text { Retención } & 5 & 2.3 \\ 1963-1964 & \text { Liquidación } & 2 & -0.9 \\ 1965-1968 & \text { Retención } & 4 & 2.9 \\ 1969-1970 & \text { Liquidación } & 2 & -1.8 \\ 1971-1977 & \text { Retención } & 7 & 3.4\end{array}$

${ }^{a}$ Respecto al último año de la fase anterior.

Fuentes: elaboración propia con base en Ministerio Agricultura, Ganadería y Pesca (2010) y Cuccia (1983, p. 118).

\section{CUADRO 4. COMPORTAMIENTO DE LAS PRINCIPALES VARIABLES DEL CICLO GANADERO}

Variable

Precios relativos

(ganaderos-agrícolas)

Existencias

Faena

Faena de vientres

Peso promedio de la faena

Tasa de extracción

Área sembrada

Consumo de carne vacuna

\section{Etapa del ciclo}

Retención

Liquidación

$\begin{array}{ll}\text { Aumenta } & \text { Disminuye } \\ \text { Aumenta } & \text { Disminuye } \\ \text { Disminuye } & \text { Aumenta } \\ \text { Disminuye } & \text { Aumenta } \\ \text { Aumenta } & \text { Disminuye } \\ \text { Disminuye } & \text { Aumenta } \\ \text { Disminuye } & \text { Aumenta } \\ \text { Disminuye } & \text { Aumenta }\end{array}$

Fuente: elaboración propia con base en Cuccia (1988). 
en el último año del periodo de retención y el primero del ciclo de liquidación, se eleva hasta 38.2\%. Contrariamente, si se considera el promedio durante el periodo de retención sin contabilizar el último año, la participación de los vientres disminuye hasta 35.2 por ciento.

Otra de las variables que aparece relacionada con el ciclo ganadero es la tasa de extracción, es decir, qué proporción representa la faena del stock de ganado vacuno. Como resulta evidente, en las fases de liquidación aumenta la tasa de extracción, mientras que ocurre lo contrario en los periodos de retención. En el largo plazo, la tasa de extracción se considera como un proxi de la evolución de la productividad ganadera, ya que su aumento tendencial reflejaría la necesidad de contar con un menor stock de ganado vacuno para un nivel de faena determinado. ${ }^{21}$

El peso de la res faenada también se encuentra asociado con la evolución del ciclo ganadero. En las fases de retención de ganado (y por lo tanto de elevados precios), los productores retienen los animales hasta que alcanzan el peso más elevado posible para maximizar su tasa de ganancia. En cambio, en las fases de liquidación de existencias, ante la perspectiva de reducción del precio, los animales se envían sin "terminar" (menor peso) al mercado, ante la necesidad de liberar superficie para el desarrollo de las actividades agrícolas.

Por último, el aumento de la superficie agrícola en las fases de liquidación de stocks y su contracción durante los ciclos de retención estuvo mediado a lo largo de la segunda fase del modelo sustitutivo de importaciones por dos factores. En primer lugar, el crecimiento del stock de ganado vacuno no se explica sólo por el aumento del área destinada a dicha actividad, sino también por los incrementos en la productividad que posibilitaron una mayor carga animal por hectárea. En segundo lugar, la remecanización del agro pampeano, al liberar tierras anteriormente destinadas a la cría de equinos, posibilitó una expansión simultánea del área dedicada a la agricultura y a la ganadería.

El nexo existente entre la evolución del stock de ganado vacuno y la superficie destinada a la producción agrícola comenzó a debilitarse desde comienzos de la década de 1960. No obstante, en los años setenta fue cuando la trayectoria de ambas variables adquirió mayor independencia,

\footnotetext{
${ }^{21}$ La evolución de la tasa de extracción a lo largo de la década de los sesenta estaría indicando un aumento en la productividad ganadera. En efecto, en los periodos de retención pasó de $22.9 \%$ en 1960-1962 a 23.4\% en 1965-1968, mientras que en los periodos de liquidación se elevó de 24.8\% en 1963-1964 a 27.2\% en 1969-1970. En este sentido, según Piñeiro y Trigo (1982), las mejoras en las prácticas de rodeo a partir de la aplicación de conocimientos disponibles en esa época (como el servicio estacionado, el control sanitario y la implantación de pasturas perennes) permitieron un progreso tecnológico en la ganadería equivalente al aumento en los rendimientos en la producción agrícola.
} 
producto de las agudas transformaciones que estaban aconteciendo en la agricultura pampeana. De todas formas, a lo largo del periodo analizado se verificaba -por regla general- que la superficie destinada a la producción agrícola comenzaba a disminuir en el último año de la fase de liquidación de ganado vacuno, de manera que durante los dos primeros años del ciclo de retención la superficie sembrada era menor que su valor promedio durante la totalidad del ciclo. A su vez, la reducción del área implantada se concentraba en el lino y en los cereales de invierno (trigo y en menor medida avena, cebada, centeno y alpiste), debido a que su mayor dispersión geográfica y su menor rendimiento por hectárea los hacía más fácilmente sustituibles por la ganadería frente a variaciones en los precios relativos. ${ }^{22}$

Por otro lado, también puede evaluarse la relación entre la rentabilidad relativa de la producción ganadera respecto de la agrícola a partir de la trayectoria diferencial del valor de los distintos tipos de tierra en la región pampeana. Si bien se observan profundas fluctuaciones, las oscilaciones resultan consistentes con las distintas fases del ciclo ganadero. En los periodos de retención de ganado vacuno y -por ende- de mayor rentabilidad relativa de dicha producción respecto a la agricultura se observa un incremento relativo en el valor de la tierra de cría, mientras que se registra el comportamiento inverso en las fases de liquidación. Durante los periodos de liquidación de ganado vacuno el precio promedio de la hectárea agrícola fue $77.8 \%$ superior a la de la zona de cría, en tanto en las fases de retención de ganado vacuno dicha relación se reduce hasta $74.6 \%$, evidenciando la modificación en la rentabilidad relativa de ambas producciones (Anuario, 2007). ${ }^{23}$

Finalmente, más allá de las fases de liquidación y retención, el precio del ganado vacuno mostró una notoria estacionalidad a lo largo de la segunda fase del modelo sustitutivo de importaciones. Las características pastoriles de la ganadería argentina conducían a que la mayoría de los productores debían reducir la carga animal por hectárea en los meses de baja producción de materia seca. En otras palabras, la oferta de ganado vacuno se incrementaba desde finales del otoño y hasta principios de la primavera independientemente de la fase del ciclo en que se encontraba, provocando una caída en los precios de este producto (Peretti y Gómez, 1991, p. 286). A su vez, Parellada (1987) demostró que la fase en la que se encontraba el ciclo ganadero modificaba la intensidad de estas variaciones estacionales. Mientras que en las fases de liquidación de ganado vacuno las modificaciones en los precios eran más agudas, sucedía lo contrario

${ }^{22} \mathrm{Al}$ respecto véase Cuccia (1988).

${ }^{23}$ En el caso de la producción ganadera se consideraron solamente los valores correspondientes a la zona de cría (zona no apta para la producción agrícola). 
en las fases de retención de stocks. Por otro lado, este autor señala que la mayor variabilidad en los precios se producía en los terneros y las vacas, mientras que novillos, novillitos y vaquillonas mostraban cambios menos pronunciados.

Las distintas fases por las que atravesó el ciclo ganadero eran determinantes también del consumo interno de carne vacuna, el cual estuvo asociado a las variaciones en el precio del producto y al poder adquisitivo de la población. En este sentido, el encarecimiento relativo de la carne vacuna en el mercado local desde mediados de los años cincuenta provocó una caída en el consumo por habitante que -más allá de las fuertes oscilaciones en el corto plazo- promedió $79.9 \mathrm{~kg}$ por año en el periodo 1960-1977, nivel inferior a $90.8 \mathrm{~kg}$ por habitante alcanzados en el primer quinquenio de los años cincuenta. Puesto que las variaciones en los niveles de consumo interno de carne vacuna a lo largo de la segunda fase de la sustitución de importaciones estuvieron asociadas con la evolución del precio local, en los periodos de liquidación de stocks y reducción del precio se expandía el consumo en el mercado doméstico, mientras que ocurría lo contrario en las fases de retención. Efectivamente, en los periodos de retención de ganado vacuno entre 1960 y 1977, el consumo promedio por habitante fue de $78.8 \mathrm{~kg}$ anuales, mientras que en las fases de liquidación alcanzó $83.5 \mathrm{~kg}$ por habitante. Sin embargo, como los precios preceden por lo general en un año a la evolución del stock de ganado vacuno, si se considera el último año del ciclo de retención y el primero del ciclo de liquidación se observa que en esos periodos el consumo alcanzó $89.4 \mathrm{~kg}$ por habitante.

De todas formas, se debe resaltar que si bien la mejora en los niveles de vida de la población fue el sustento material sobre el que se basó la expansión del mercado local de carne vacuna, no se observa una asociación estrecha entre el consumo de carne vacuna y la evolución de los salarios reales. Por el contrario, pese a que ambas variables tuvieron un comportamiento creciente en la etapa, presentaron una evolución dispar.

En resumen, la relativa estabilidad del consumo en el mercado local y su tendencia creciente a lo largo del periodo en consideración fueron la base de sustentación de la expansión del stock ganadero, en donde la faena destinada al mercado interno representó en promedio $75.2 \%$ de la producción. En este contexto, las exportaciones estaban circunscritas a la existencia de excedentes en la economía local, que se producían por lo general en las fases de aumento de la faena de ganado vacuno.

El incremento de las exportaciones en las fases de liquidación de stocks $y$, por ende, de reducción de los precios tuvo profundas implicancias en el aprovechamiento de las oportunidades que brindaba el mercado mundial, ya que las mayores colocaciones en los mercados externos iban acompañadas, en general, por una reducción en el precio (véase gráfica 1). Si bien, 

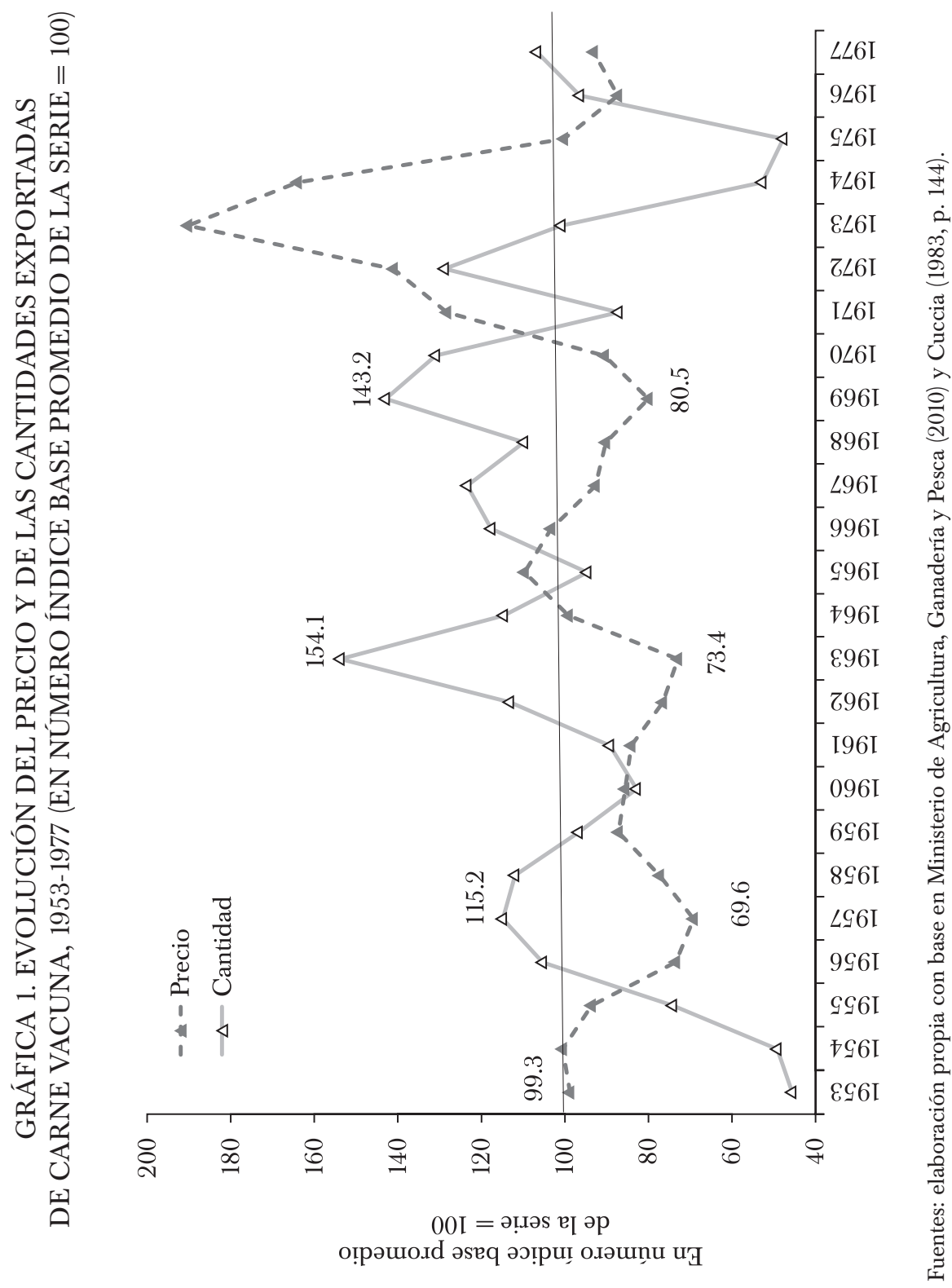
en determinados periodos, se aplicaron políticas tendentes a restringir el consumo de carne vacuna en el mercado local de manera de aumentar los excedentes plausibles de ser exportados, las mismas tuvieron poco éxito. ${ }^{24}$ A su vez, se debe destacar, que la reducción del precio no ocurría como consecuencia de los mayores volúmenes exportados por Argentina, sino debido a que el incremento de las exportaciones se producía, por lo general, en las fases de sobreoferta a escala internacional. Es decir, Argentina aumentaba recurrentemente sus exportaciones de carne vacuna en los periodos de contracción de los precios internacionales. ${ }^{25}$

$\mathrm{El}$ análisis realizado a lo largo de esta sección permitiría inferir que la falta de dinamismo de las exportaciones de carne vacuna de Argentina estuvo acompañada por una pérdida de relevancia de los mercados internacionales en la determinación del precio de la carne vacuna en el mercado local y, en definitiva, en la evolución del ciclo ganadero. Sin embargo, tal como se analizará en la próxima sección, a pesar de la disminución de las exportaciones cárnicas argentinas, el mercado internacional continuó desempeñando un papel central en la evolución de la ganadería argentina al afectar el precio interno de este producto.

\section{LA RELACIÓN ENTRE EL CICLO GANADERO LOCAL E INTERNACIONAL}

La evolución del ciclo ganadero en Argentina tras la finalización de la segunda guerra mundial estuvo estrechamente asociada al comportamiento experimentado en el mercado internacional cárnico, ya que a pesar de la pérdida de importancia de las exportaciones de este producto la faena destinada a los mercados internacionales -aunque decreciente- era aún significativa. Efectivamente, la evolución del precio internacional de la carne vacuna estuvo asociada, por lo general, con la fase del ciclo en el que se encontraban la mayor parte de los países importadores. Estos países regulaban los volúmenes de las importaciones de carne -mediante aranceles móviles o cuotas- reduciéndolas en los periodos de liquidación e incrementándolas ante problemas de abastecimiento de la demanda en

${ }^{24} \mathrm{Al}$ respecto, Reca y Gaba (1973) sostienen que "la primera veda al consumo interno se estableció en 1952 y si bien sólo fue suspendida tres años después, de hecho cesó de funcionar aproximadamente al año y medio de ser aplicada. La segunda veda (años 1964 y 1965) introdujo la restricción a la venta de carne vacuna dos días por semana y la última, a partir de marzo de 1971, si bien con interrupciones y contramarchas, se ha caracterizado por fijar la duración de la veda en una semana, hasta su derogación en abril de 1973” (p. 336).

${ }^{25}$ Este aspecto es mencionado en forma general por Perren (2006) quien sostiene: "The problem in the beef exports market of these years were mainly because the current beef production cycles in most of major producing countries were approaching their peak at the same time" (p. 178). 
las fases de retención, de manera de lograr la estabilidad de los precios en sus respectivas economías.

De esta forma, ante el inicio de una fase de retención -restricción de la oferta- en los principales países importadores, se reducían las trabas al ingreso de carne vacuna, aumentando el flujo comercial y con ello el precio internacional. En cambio, ante la depresión de los precios internos en los países importadores se agudizaban las limitaciones al comercio exterior, provocando una reducción en los precios internacionales que repercutía -a su vez- en el ciclo ganadero de los países exportadores. El aumento de la faena de ganado vacuno en Europa occidental -que era el mayor mercado de exportación para las carnes argentinas- traía aparejado una reducción en el precio de las exportaciones argentinas (véase gráfica 2). Si bien la asociación entre dichas variables dista de ser perfecta, existe una clara relación entre la evolución de la oferta interna de carne vacuna en Europa occidental y los precios de las exportaciones argentinas hasta mediados de los años setenta.

Por lo tanto, la evolución del ciclo ganadero en la economía argentina estaba influida por la evolución del mercado mundial de carne vacuna, aunque las exportaciones argentinas fueran decrecientes. Las variaciones en las cantidades demandadas y la modificación en los precios internacionales conducían a la asociación del ciclo local con el de los principales países importadores. En otras palabras, desde mediados de los años cincuenta hasta mediados de los setenta, las fases de retención y liquidación en Argentina mostraron una estrecha relación con el comportamiento del ciclo en los países europeos, en particular con el Reino Unido.

De esta forma, el inicio de una fase de retención-liquidación en los países importadores determinaba una variación en el precio internacional que se trasladaba -en mayor o menor medida- a la economía argentina. Si bien a lo largo de este periodo se aplicaron diversas medidas tendentes a desvincular el precio local de la evolución del mercado internacional (como la aplicación de tipos de cambio diferenciales o el control de precios en el mercado interno, entre otras), hasta comienzos de los años setenta existió una estrecha relación entre ambos. Es más, los precios en la economía local mostraron una elevada sensibilidad a los cambios en los precios internacionales, ya que tanto en las fases de alza como en las de reducción lo hicieron a tasas más elevadas que los precios internacionales (véase gráfica 3).

Una excepción a esta tendencia fue el año 1973, en donde el aumento en el precio internacional de la carne vacuna no fue acompañado por un incremento de igual magnitud en los precios internos, marcando una diferenciación con el periodo previo. Esta modificación en el patrón de comportamiento de los precios internos se debió esencialmente a la abrupta 


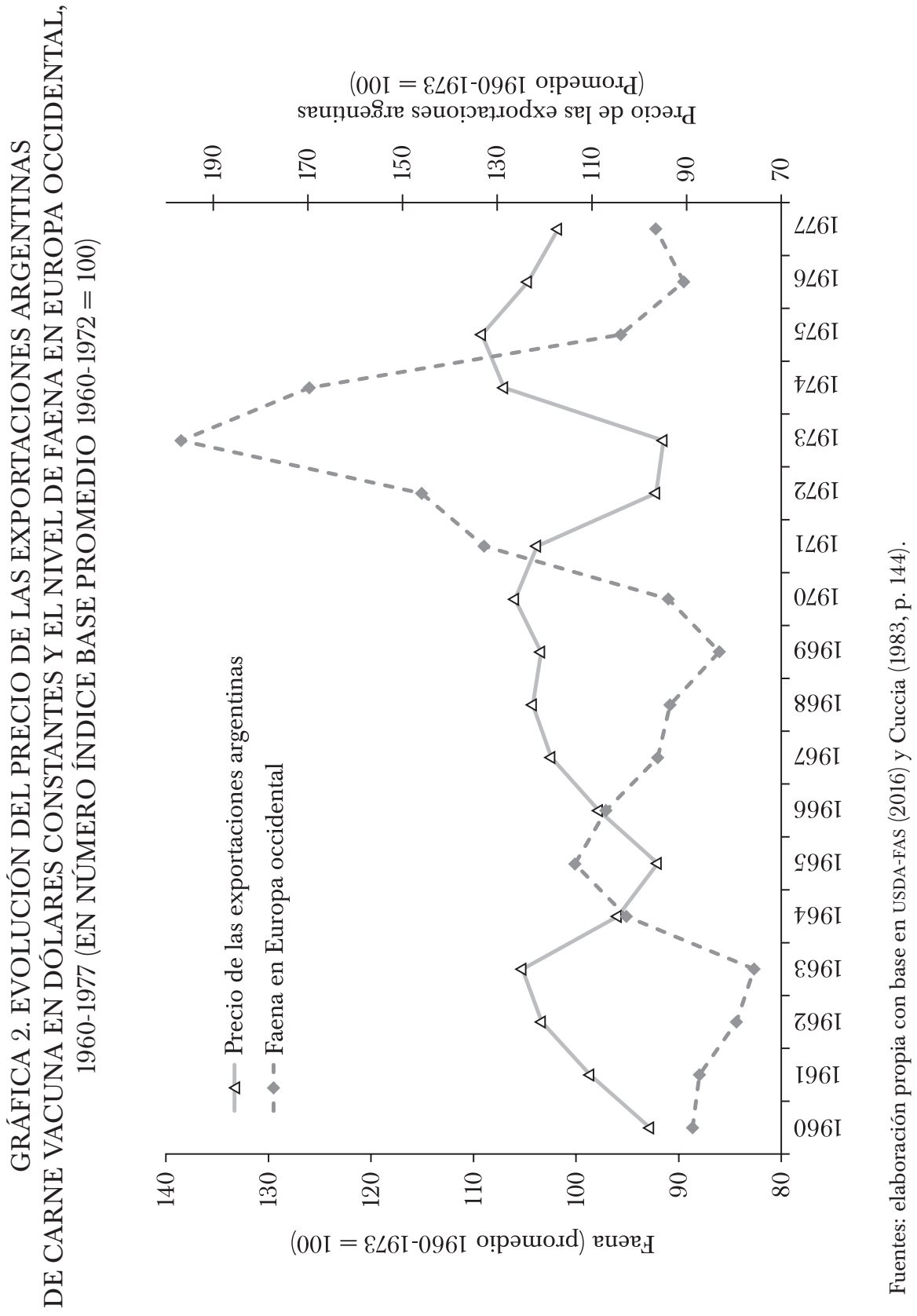




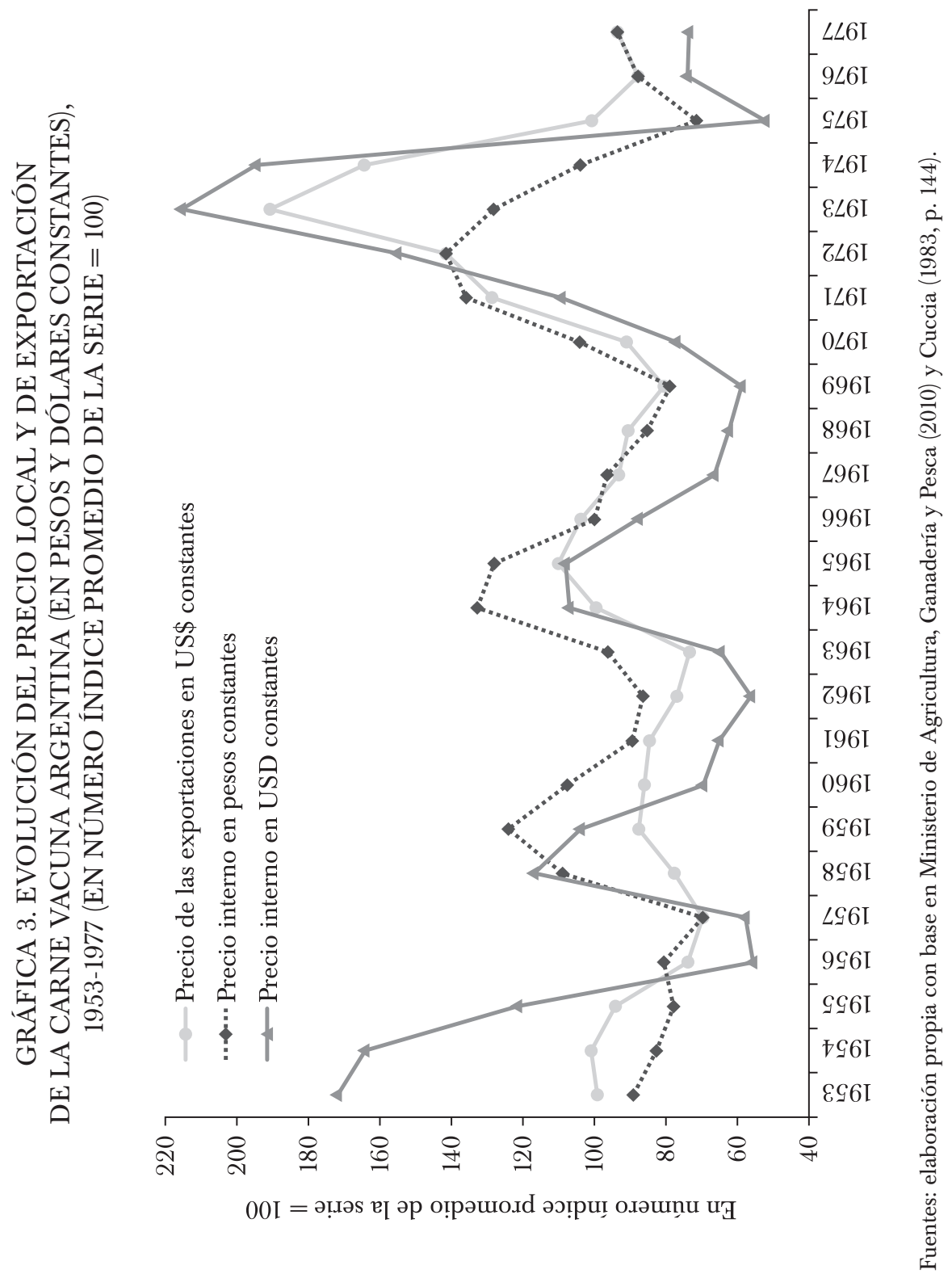


variación del valor de la moneda local, que se apreció $54.9 \%$ respecto al promedio registrado en el periodo comprendido entre 1960 y 1972, permitiendo de esta forma reducir el impacto de la suba de los precios internacionales en el mercado local. En consecuencia, la evolución de los precios locales e internacionales estuvo mediada -a su vez- por el tipo de cambio vigente a lo largo del periodo en consideración. $\mathrm{Al}$ analizarse la evolución del precio local en dólares se observa que mantiene la tendencia en relación con el precio internacional, aunque las variaciones en la economía local durante el primer quinquenio de los años cincuenta fueron más intensas que las registradas en términos del poder de compra interno. Este proceso encuentra su explicación en la sobrevaluación de la moneda durante el segundo gobierno peronista, que estuvo $57.6 \%$ por debajo del tipo de cambio real registrado en la década de 1960. A su vez, con excepción de 1965 , los precios en dólares en la economía local sobrerreaccionaron a la evolución de los precios internacionales, tanto en las fases de expansión como en las de contracción.

Por lo general, la fase depresiva de los precios de la carne vacuna era más aguda en el mercado local que en el internacional. En tanto, tal como analizó Cuccia (1988), frente a la elevación de los precios internos ante cambios en la demanda internacional se generaban conflictos económicos y políticos debido al efecto de este fenómeno sobre los salarios reales. Este proceso conducía a la aplicación de vedas, precios máximos y reducción del tipo de cambio efectivo para la carne, entre otras medidas, que pretendían amortiguar la variación de los precios domésticos. ${ }^{26}$

Más allá de las oscilaciones comentadas, la notoria asociación entre los precios locales y los internacionales condujo a la convergencia entre el ciclo ganadero local y el de los principales países importadores, tendencia que se puede verificar al compararse los niveles de faena -indicador clave del ciclo ganadero- en Argentina y en su principal país importador hasta comienzos de los años setenta, el Reino Unido (véase gráfica 4).

La ausencia de correlación entre los niveles de faena en Argentina y en el Reino Unido a partir de finales de los años sesenta se debió fundamentalmente a los brotes de fiebre aftosa registrados en el país europeo en los años 1967-1968 y 1969-1970, que determinaron prácticamente el cierre de dicho mercado para las exportaciones vacunas argentinas. Como se señaló anteriormente, la imposibilidad de acceder al mercado británico fue compensada hasta mediados de los años setenta por un incremento de

\footnotetext{
${ }^{26} \mathrm{Al}$ respecto, Cuccia (1988) sostiene: "La retención culmina dando paso a una nueva fase contractiva, cuando la faena interna en los países importadores crece como resultado de la retención, reduciéndose los precios internacionales y por lo tanto los precios internos. Por lo común, en la Argentina, la política cambiaria y de precios en general, aparentemente habría acelerado dicho proceso." (p. 52).
} 

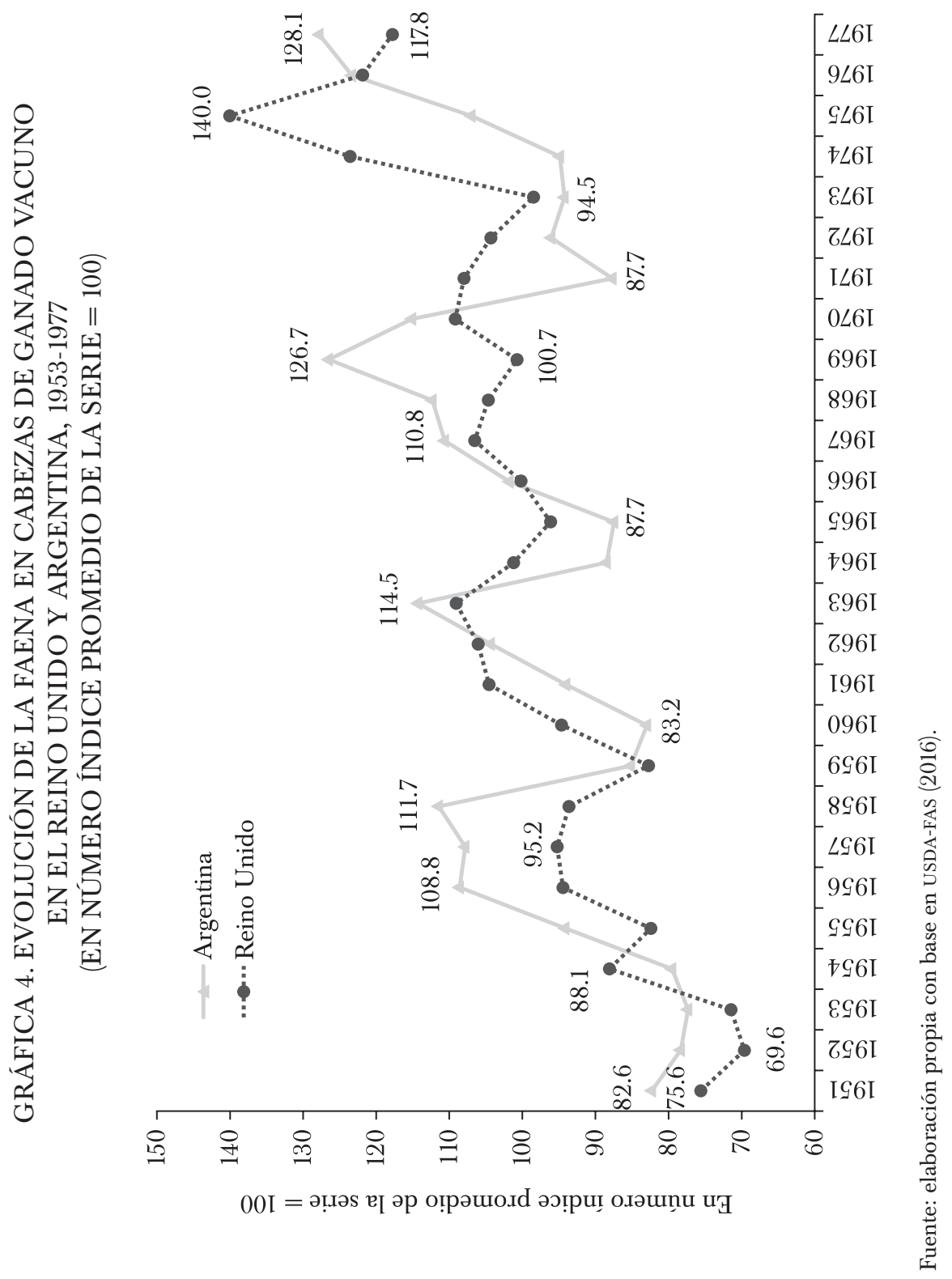
las exportaciones hacia otros países de Europa occidental. En este sentido, se observa la misma asociación si se comparan los niveles de faena hasta mediados de los años setenta no sólo con los del Reino Unido, sino con los de Europa occidental en su conjunto (véase gráfica 5).

El vínculo entre el ciclo ganadero local y el internacional se diluyó a mediados de los años setenta como consecuencia de los profundos cambios que se venían gestando desde comienzos de la década previa en el mercado internacional de carne vacuna y, también, en la economía argentina. La reducción de las exportaciones argentinas, como consecuencia del cierre de los mercados de exportación del circuito aftósico conjuntamente con el progresivo autoabastecimiento que alcanzaron los países europeos, condujo a una creciente diferenciación entre la evolución de los precios en el mercado interno y los vigentes en el mercado mundial.

Se debe señalar que la disminución de las ventas ganaderas al exterior desde mediados de los años setenta produjo un incremento de la participación del mercado local en la oferta ganadera total. Mientras que durante el primer quinquenio de los años setenta se destinó en promedio $26 \%$ de la faena al abastecimiento de los mercados externos, en la primera mitad de la década de 1980 dicha proporción se había reducido a 16.1 por ciento.

En este contexto, por lo tanto, la evolución del precio de la carne vacuna en el mercado local quedó supeditada al comportamiento de la demanda doméstica, diluyéndose progresivamente la asociación existente verificada durante la segunda fase del modelo sustitutivo de importaciones entre el ciclo ganadero local y el internacional. Más aún, cuando se asistió a una sensible contracción en el precio local de la carne vacuna en el segundo quinquenio de la década de 1970, por razones de índole interna a la economía argentina, tal como se analizará en la última sección de este trabajo.

\section{REFLEXIONES FINALES}

La declinación en los mercados internacionales de carne vacuna por parte de Argentina estuvo estrechamente relacionada con la pérdida de hegemonía de Gran Bretaña tras la finalización de la segunda guerra mundial. Mientras que con anterioridad al conflicto bélico Gran Bretaña daba cuenta de $77 \%$ de las importaciones de carne vacuna a escala mundial, dicho porcentaje se había reducido a menos de $10 \%$ en el primer quinquenio de los años setenta. A su vez, la incapacidad de Argentina, y de la inmensa mayoría de los países de América del Sur, de erradicar la fiebre aftosa de sus rodeos los privó de la posibilidad de sustituir el mercado británico por otros mercados en expansión, como el estadunidense, que en el mismo 

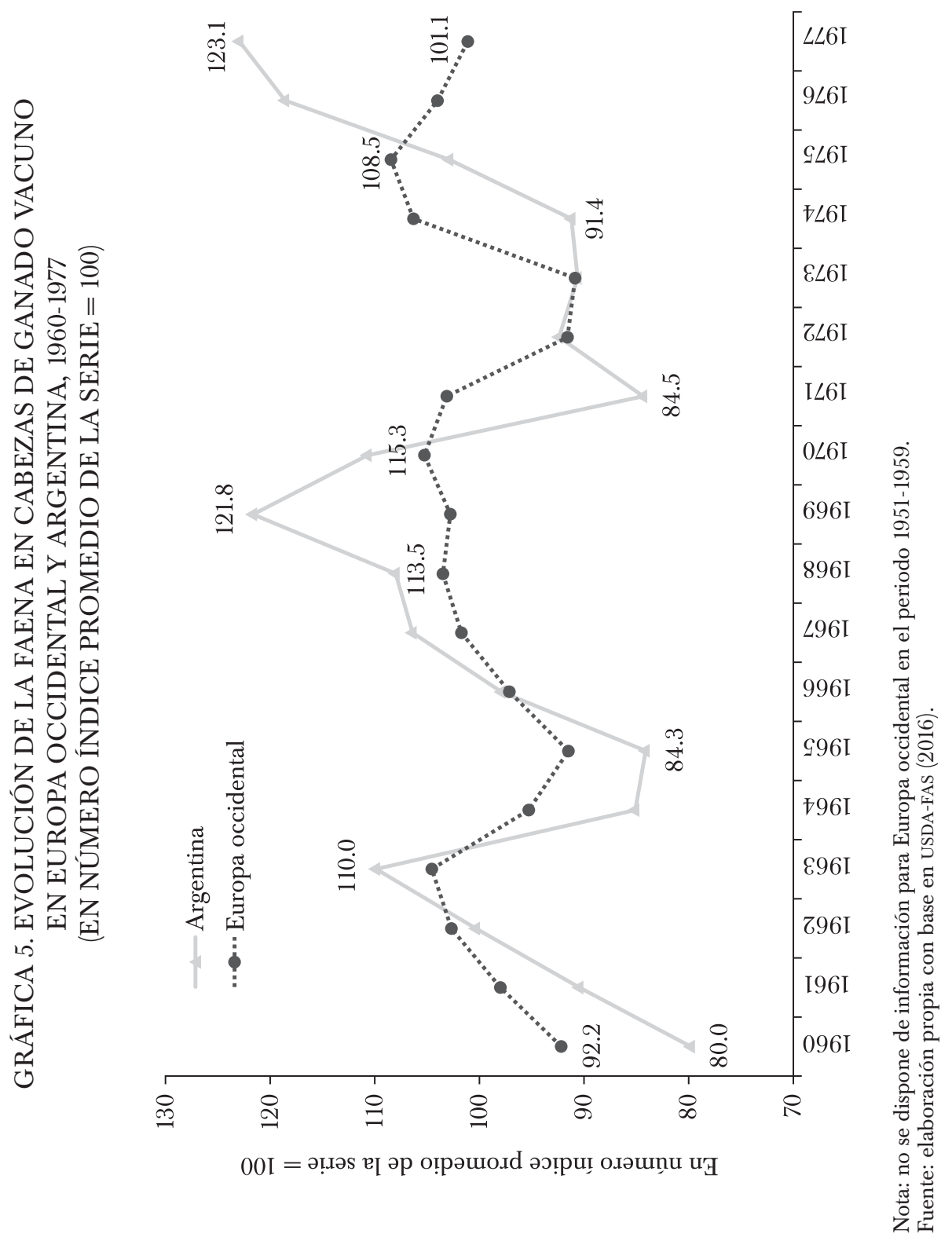
periodo incrementó su peso en el mercado internacional cárnico de 4 a 30\% (Cuccia, 1988).

Si bien las exportaciones argentinas de carne vacuna perdieron relevancia en el mercado mundial durante la segunda fase del modelo sustitutivo de importaciones, en el mercado local se asistió a una expansión muy significativa del stock de ganado vacuno. Estos procesos no implicaron, sin embargo, que el ciclo ganadero local se independizara del internacional. Por el contrario, tal como se analizó, la evolución del ciclo ganadero en Argentina estuvo asociada al ciclo en los principales países importadores de carne vacuna del circuito aftósico. La ruptura de esta relación a mediados de la década del setenta obedeció a modificaciones en el mercado internacional cárnico, como fue el creciente autoabastecimiento de los países de Europa occidental, pero fundamentalmente al nuevo patrón de crecimiento adoptado en la economía argentina. Efectivamente, una vez garantizados niveles mínimos de rentabilidad, el uso de la tierra estaba determinado por la estructura de precios relativos entre la producción agrícola y la ganadera. Sin embargo, la reforma financiera aplicada en 1977 en Argentina transformó abruptamente esta lógica de comportamiento, al incluir un nuevo precio en la determinación del uso de la tierra. Por lo tanto, el destino del uso del suelo ya no sólo se regía por la evolución de los precios relativos entre la producción ganadera y la agrícola, sino también por los rendimientos en el circuito financiero, tasa de interés.

En este contexto, la ventaja relativa de los rendimientos financieros sobre los precios agrícolas y ganaderos impulsó, salvo años excepcionales, una subutilización del suelo en el largo plazo, cuyo correlato fue la salida sistemática de recursos del sector agropecuario pampeano hacia la actividad financiera. De esta forma, tanto durante la segunda mitad de los años setenta como a lo largo de los años ochenta, se asistió a una contracción simultánea del stock de ganado vacuno y de la superficie destinada a la agricultura (aunque aumentó su producción con base en el incremento de la productividad, en especial en la zona núcleo).

En otras palabras, las ventajas relativas de los rendimientos financieros sobre la producción agropecuaria condujeron a una sensible declinación de la superficie utilizada con fines productivos. Este proceso fue más intenso en la producción ganadera, en virtud de su menor rentabilidad relativa respecto a la producción agrícola y a las colocaciones en el sistema financiero.

En definitiva, el nuevo patrón de crecimiento adoptado por la dictadura militar redujo la producción agrícola potencial y al mismo tiempo exacerbó la liquidación de ganado vacuno ante una estructura de precios relativos de por sí desfavorable para la producción ganadera respecto a la agrícola. En el año 1977 se inició la fase de liquidación de ganado vacuno 
más significativa de la historia argentina, que perduró hasta 1988 y en la cual se liquidaron cerca de 14000000 de cabezas de ganado. Es más, este proceso, como era de esperar, fue acompañado por una abrupta reducción en el precio local de la carne vacuna que se abarató entre 1978 y 1988 $19.4 \%$ respecto a los valores prevalecientes durante la segunda fase del modelo sustitutivo de importaciones.

En este marco, la reducción de los salarios reales como consecuencia de las políticas adoptadas por la dictadura militar en 1976 no fue acompañada por una reducción en el consumo de carne vacuna. Por el contrario, durante 1976 y 1977 se superaron los niveles de consumo por habitante registrados a lo largo de la década de 1960 y comienzos de la década de 1970, debido al derrumbe del precio local ante el inicio de la fase de liquidación de ganado vacuno más intensa de la historia de Argentina. Por lo tanto, la disolución de la asociación existente entre el ciclo ganadero local y el prevaleciente en los principales países importadores de carne vacuna proveniente de Argentina a mediados de los años setenta obedeció más a causas endógenas a la economía argentina que a la disminución de las exportaciones hacia los países europeos.

Esto queda en evidencia cuando se analiza la evolución del stock de ganado vacuno en otros países de la región, los cuales enfrentaban limitantes similares en el acceso a los mercados internacionales, pero que no verificaron una aguda contracción en su stock ganadero ante la contracción del mercado internacional. Por ejemplo, Brasil y Paraguay expandieron su stock de ganado vacuno entre mediados de las décadas de 1970 y 1980 en aproximadamente 20\%. Mientras que en Argentina y, en menor medida, en Uruguay, con modelos de crecimiento basados en la persistencia de elevadas tasas de interés en el mercado financiero local, se redujo el stock de ganado vacuno. ${ }^{27}$

\section{LISTA DE REFERENCIAS}

Anuario del Campo Argentino 2005-2006 (2007). Argentina: Diario La Nación.

AzcuY-Ameghino, E. (2007). La carne vacuna argentina: historia, actualidad y problemas de una agroindustria tradicional. Argentina: Imago Mundi.

BARSky, O. y Gelman, J. (2001). Historia del agro argentino. Desde la conquista hasta fines del siglo XX. Argentina: Grijalbo-Mondadori.

BASUALDO, E. (2006). Estudios de historia económica argentina. Desde mediados del siglo XX a la actualidad. Argentina: Siglo XXI.

${ }^{27}$ Con base en FAO (2016), el stock de ganado vacuno entre 1975 y 1985 incrementó 19.7\% en el caso de Brasil, 19.9\% en Paraguay, en tanto se redujo 11.6\% en Argentina y 7.3\% en Uruguay. 
Am. Lat. Hist. Econ., año 24, núm. 3, septiembre-diciembre, 2017, pp. 161-192

Bearzotti de Noceti, S. (1983). El proceso de mecanización agrícola en la Argentina: sus principales etapas (Documento de trabajo, núm. 4). Argentina: Instituto Nacional de Tecnología Agropecuaria.

BISANG, R. (2008). El desarrollo agropecuario en las últimas décadas. ¿Volver a creer? En B. Kosacoff (ed.), Crisis, recuperación y nuevos dilemas. La economía argentina 2002-2007 (pp. 187-260). Argentina: CEPAL.

Brusca, E. y BisAng, R. (2016). Cambios estructurales en el ciclo ganadero argentino. Revista Argentina de Economía Agraria, 14(1), 7-29.

CuCCIA, L. (1983). El ciclo ganadero y la economía argentina: indicadores y análisis de su evolución: 1953-1979. Chile: CEPAL.

Cuccia, L. (1988). Tendencias y fluctuaciones del sector agropecuario pampeano. Argentina: CEPAL.

Díaz-Alejandro, F. (1975). Ensayos sobre la historia económica argentina. Argentina: Amorrortu.

Fernández, R. (2011). El ciclo ganadero y el modelo de Díaz Alejandro (Documentos de trabajo, núm. 465). Argentina: Universidad Centro de Estudios Macroeconómicos de Argentina.

Food and Agriculture Organization of the United Nations (FaO) (2016). Livestock primary (production) and animal live (production). Recuperado de: www.fao.org/ faostat/en/\#home

Giberti, H. (1974). Historia económica de la ganadería Argentina. Argentina: Solar/ Hachette.

Gluck, S. (1977). Anatomía del ciclo ganadero argentino. Ensayos Económicos, 1, 59-89.

Gómez, P., Peretti, M., Pizarro, J. y Cascardo, A. (1991). Sistemas de producción predominantes. En O. BARSKY (ed.), El desarrollo agropecuario pampeano (pp. 95146). Argentina: Grupo Editor Latinoamericano.

GonzÁlez, J. (2005). Lineamientos para la formulación de escenarios del mercado de carne vacuna en la Argentina (Documento de trabajo, núm. 1). Argentina: Instituto de Promoción de la Carne Vacuna Argentina.

GuAdAGni, A. (1964). Estudio econométrico del consumo de carne vacuna en argentina en el periodo 1914-1959. Desarrollo Económico, 3(4), 517-533. DOI: 10.2307/3465788

Guadagni, A. y Petrecolla, A. (1965). La función de demanda de carne vacuna en la Argentina en el periodo 1935-1961. El Trimestre Económico, 32(126), 261-290. Recuperado de http://www.jstor.org/stable/20855793

Mallon, R. y Sourrouille, J. (1973). La política económica en una sociedad conflictiva: el caso argentino. Argentina: Amorrortu.

MARTínez DE Hoz, J. A. (1967). La agricultura y la ganadería argentina en el periodo 19301960. Argentina: Sudamericana.

Melo, E. C. y LóPez, A. (2002). Control de la fiebre aftosa: la experiencia americana. Revue Scientifique et Technique: International Office of Epizootics, 21(3), 689-694. 
Ministerio de Agricultura, Ganadería y Pesca de la República Argentina (2010). Indicadores del sector bovino. Argentina: Dirección de Análisis Económico Pecuario-Subsecretaría de Ganadería.

O’Connell, A. (1986). La fiebre aftosa, el embargo sanitario norteamericano contra las importaciones de carne y el triángulo Argentina-Gran Bretaña-Estados Unidos en el periodo entre las guerras mundiales. Desarrollo Económico, 26(101), 21-50. DOI: $10.2307 / 3466793$

Parellada, G. (1987). Análisis de la estacionalidad y del ciclo de la ganadería vacuna argentina. Algunas propuestas de estabilización. Argentina: Instituto Interamericano de Cooperación para la Agricultura.

Parellada, G. (1988). Evaluación de la variabilidad cíclica y estacional de los precios y la oferta de carne vacuna: un análisis de las políticas de estabilización. Argentina: Instituto Interamericano de Cooperación para la Agricultura.

Peretti, M. y Gómez, P. (1991). Evolución de la ganadería. En O. Barsky (ed.), El desarrollo agropecuario pampeano (pp. 261-306). Argentina: Grupo Editor Latinoamericano.

Perren, R. (2006). Taste, trade and technology: The development of the international meat industry since 1840. United Kingdom: Ashgate Publishing.

Piñeiro, M. y Trigo, E. (1982). Cambio técnico y modernización en el sector agropecuario de América Latina: un intento de interpretación. Desarrollo Económico, 27(84), 435-468. DOI: 10.2307/3466609

RECA, L. (1972). Consumo interno y exportación de carne vacuna: interpretación de una experiencia reciente. Estudios de la Economía Argentina, 12, 79-93.

RECA, L. y GABA, E. (1973). Poder adquisitivo, veda y sustitutos: un reexamen de la demanda interna de carne vacuna en la Argentina, 1950-1972. Desarrollo Económico, 13(50), 333-346. DOI: 10.2307/3466170

United States Department of Agriculture. Foreign Agricultural Service [USDAFAS] (2016). Production, Supply and Distribution (PSED). Recuperado de: https:// apps.fas.usd.gov/psdonline/app/index.html\#/app/downloads

\section{Bibliografía}

Bisang, R. (2003). Las tramas de carnes bovinas en Argentina. Argentina: Secretaría de Política Económica/CEPAL. 